\title{
Kinesin-Like Protein KIF23
}

National Cancer Institute

\section{Source}

National Cancer Institute. Kinesin-Like Protein KIF23. NCI Thesaurus. Code C104163.

Kinesin-like protein KIF23 (960 aa, 110 kDa) is encoded by the human KIF23 gene. This protein is involved in mitotic spindle assembly, cytokinesis and microtubule-dependent motor activity. 